\title{
The Ultimate Pile Bearing Capacity from Conventional and Spectral Analysis of Surface Wave (SASW) Measurements
}

\author{
Nor Faizah Bawadi ${ }^{1 *}$, Shamilah Anuar ${ }^{1}$, Mustaqqim A.Rahim ${ }^{1}$, and A.Faizal Mansor ${ }^{2}$ \\ ${ }^{1}$ School of Environmental Engineering, Universiti Malaysia Perlis, Kompleks Pengajian Jejawi 3, \\ 02600 Arau, Perlis, Malaysia \\ ${ }^{2}$ Faculty of Engineering Technology (Civil), Universiti Malaysia Perlis, Aras 1, Blok S2, Kampus \\ UniCITI Alam, Sungai Chuchuh, Padang Besar, Perlis, Malaysia
}

\begin{abstract}
A conventional and seismic method for determining the ultimate pile bearing capacity was proposed and compared. The Spectral Analysis of Surface Wave (SASW) method is one of the non-destructive seismic techniques that do not require drilling and sampling of soils, was used in the determination of shear wave velocity $\left(\mathrm{V}_{\mathrm{s}}\right)$ and damping (D) profile of soil. The soil strength was found to be directly proportional to the Vs and its value has been successfully applied to obtain shallow bearing capacity empirically. A method is proposed in this study to determine the pile bearing capacity using $\mathrm{V}_{\mathrm{s}}$ and $\mathrm{D}$ measurements for the design of pile and also as an alternative method to verify the bearing capacity from the other conventional methods of evaluation. The objectives of this study are to determine $V_{s}$ and $D$ profile through frequency response data from SASW measurements and to compare pile bearing capacities obtained from the method carried out and conventional methods. All SASW test arrays were conducted near the borehole and location of conventional pile load tests. In obtaining skin and end bearing pile resistance, the Hardin and Drnevich equation has been used with reference strains obtained from the method proposed by Abbiss. Back analysis results of pile bearing capacities from SASW were found to be $18981 \mathrm{kN}$ and $4947 \mathrm{kN}$ compared to $18014 \mathrm{kN}$ and $4633 \mathrm{kN}$ of IPLT with differences of $5 \%$ and $6 \%$ for Damansara and Kuala Lumpur test sites, respectively. The results of this study indicate that the seismic method proposed in this study has the potential to be used in estimating the pile bearing capacity.
\end{abstract}

\section{Introduction}

The valuable consideration on basic soil parameters should be implemented in evaluation of pile bearing capacity using various conventional methods laboratory or from in-situ testing. Generally, the in-situ seismic method commonly used for evaluating pile bearing

\footnotetext{
* Corresponding author: norfaizah@unimap.edu.my
} 
capacity because of difficulty and cost of collecting a good sample for laboratory testing. The effectiveness of this seismic method obtained more stable and reliable when compared with those of the conventional methods [1]. This study was conducted to evaluate the ultimate bearing capacity of pile at sites located on residual soils in Damansara and Kuala Lumpur, Malaysia. The Spectral Analysis of Surface Wave (SASW) test has been conducted to measure shear wave velocity $\left(\mathrm{V}_{\mathrm{s}}\right)$ and damping (D) values based on SASW data interpretation. Data from Instrumented Pile Load Test (IPLT) are back calculated with shear wave velocity and damping value, and can be used in evaluation of pile bearing capacity in residual soils. Indirectly, the results of the pile bearing capacity obtained using shear wave velocity and damping measurements was compared with IPLT's results.

\section{Basic parameters of SASW measurement}

It is a common practice to determine the bearing capacity of foundation based on the shear wave velocity and damping measurements carried out as part of the field testing. Basically, shear wave velocity only travel in the matrix of soil particles and does not travel in its liquid part. This characteristic of shear wave velocity enables it to measure the effective soil strength in which it travels. The good agreement has been shown with the travelling shear wave causes minute strain and its measurement is known to be elastic and hence the dynamic shear modulus [2]. The consideration of overburden pressure $\left(\sigma^{\prime}{ }_{v}\right)$ in evaluation of penetration resistance [3], the measured $\mathrm{V}_{\mathrm{s}}$ obtained from SASW testing should be normalized $\left(\mathrm{V}_{\mathrm{s} 1}\right)$ based on relation of atmospheric pressure $\left(\mathrm{P}_{\mathrm{a}}\right)$ using Equation (1).

$$
\mathrm{V}_{\mathrm{s} 1}=\mathrm{V}_{\mathrm{s}}\left(\mathrm{P}_{\mathrm{a}} / \sigma_{\mathrm{v}}^{\prime}\right)
$$

Initial shear modulus can be defined as shear modulus at infinitely small-strain amplitude. It is therefore necessary to obtain shear strain amplitude in soil deposits when the SASW test is to be conducted. The dynamic shear strain $(\gamma)$ is defined as the ratio of peak particle velocity $(v)$ to shear wave velocity $\left(V_{s}\right)$ as presented in Equation (2) [4-5].

$$
\gamma=\mu / \mathrm{V}_{\mathrm{s}}
$$

At small-strain conditions, particle motion resulting from propagation of shear waves is non-destructive. As shear strain increases, the initial shear modulus will decrease from the maximum small-strain value. In-situ tests have commonly been assumed to be small-strain and the measurement of shear wave velocity will be directly related to the maximum shear modulus [6]. The appropriate shear strain must be known, as well as the appropriate modulus reduction with increasing shear strain. Researcher state that damping refers to the energy dissipation within a soil mass during dynamic loading [7]. For small value of material damping, the quality factor and damping ratio can be defined as the resonance frequency divided by the bandwidth $[3,8]$. Originally, the half-power bandwidth method has been developed to determine the damping ratio of a structure from the width of the peaks in the structure's frequency response function in the field of structural dynamics.

The strain amplitudes affecting damping ratio of soil [9]. The determination of the damping ratio established $[3,10,11,12]$. The relationship of damping and shear strains [13], the characteristic of normal or shear strain can be determined using rearrangement of the Equation (3) as shown below:

$$
\mathrm{D}=\mathrm{D}_{\max } /\left[1+\ln \left(1+(\mathrm{e}-1)\left(\gamma_{\mathrm{r}} / 2 \gamma\right)\right)\right]
$$


where $\mathrm{D}_{\max }$ is maximum damping at $33 \%$, $\mathrm{D}$ is damping ratio; $\gamma$ is shear strain at damping measured; e is constant and $\gamma_{\mathrm{r}}$ is characteristics shear strain.

\section{Pile bearing capacity using SASW measurement}

Soil dynamics tests under cyclic loading, both in normal triaxial or shear test have shown common hysteretic behavior. The skeleton of the backbone curve of the hysteresis to express form of hyperbolic stress-strain soil model [9]. Based on this approaches, the normal $(\sigma)$ and shear stress $(\tau)$ of soil can be defined using the following equation:

$$
\begin{aligned}
& \sigma=\left(E_{0} \varepsilon\right) /\left(\left(1+\left(\varepsilon / \varepsilon_{r}\right)\right)\right) \\
& \tau=\left(\mathrm{G}_{0} \gamma\right) /\left(\left(1+\left(\gamma / \gamma_{\mathrm{r}}\right)\right)\right)
\end{aligned}
$$

where $\mathrm{E}_{0}$ and $\mathrm{G}_{0}$ are elastic and shear modulus at small-strain (less than $10^{-4} \%$ ); $\varepsilon$ and $\gamma$ are normal and shear strain under pile load respectively. The ultimate pile bearing capacity $\left(Q_{u l t}\right)$ can be obtained by estimating the stress generated around the pile that contacted to the soil. Consideration of stress-strain behavior of soil has been used in evaluation of total skin resistance $\left(\mathrm{Q}_{\mathrm{s}}\right)$ and end bearing $\left(\mathrm{Q}_{\mathrm{b}}\right)$ of pile.

\section{Methodology}

This study is mainly dividing into two stages. The first stage deals with field configuration and data acquisition in order to determine the data of shear wave velocity and damping. The basic configuration of the source and receivers used in the field testing using the Common Array Profiling (CAP) [14]. There are two numbers of the geophone sensor used which having a natural frequency of $1 \mathrm{~Hz}$ and calibration factor is $400 / \mathrm{V} /(\mathrm{m} / \mathrm{s})$. Several assorted hammers comprise a small geology, rubber, steel and steel sledge hammer were employed to generate energy over the required frequency ranges. The output of SASW data analysis to obtain shear wave velocity profile, dynamic shear strain and damping ratio of soil.

Meanwhile, in the second stage, the back analysis on estimation of pile bearing capacity of a pile using shear wave velocity and damping measurements. The skin resistance and end bearing of the pile were then calculated [9] and the SASW data covered relevant shear wave velocity, damping and dynamic shear strain amplitude at measured damping. In addition, prediction of soil density and shear modulus has been correlated to the shear wave velocity [15]. By back calculated strain amplitudes data, the ultimate pile bearing capacity evaluated and the results of pile bearing capacity in second stage were then compared to the results of IPLT.

\section{Results and discussions}

The SASW data were carried out using the National Instrument USB6289 data acquisition system with the WinSASW 3.2.12 and analysis software. The measured shear wave velocity, damping and $\mathrm{N}$-value for tested sites are shown in Table 1. The distribution pattern of $\mathrm{V}_{\mathrm{s}}$ and $\mathrm{N}_{\text {value }}$ at the both tested sites indicate that the $\mathrm{V}_{\mathrm{s}}$ profile similar to the SPT profile which the parameters increased proportionally with depth. 
Table 1. Results of shear wave velocity, damping and $\mathrm{N}_{\text {value }}$ for site of Kuala Lumpur and Damansara.

\begin{tabular}{|c|c|c|c|c|}
\hline \multirow{3}{*}{ Sites } & \multicolumn{4}{|c|}{ Soil Parameters } \\
\cline { 2 - 5 } & Depth, z (m) & $\mathrm{N}_{\text {value }}$ & $\begin{array}{c}\text { Shear Wave } \\
\text { Velocity, V }(\mathrm{m} / \mathrm{s})\end{array}$ & $\begin{array}{c}\text { Damping, D } \\
(\%)\end{array}$ \\
\hline \multirow{3}{*}{$\begin{array}{c}\text { Kuala } \\
\text { Lumpur }\end{array}$} & $0-3$ & $8-20$ & $100-250$ & $0.065-0.069$ \\
\cline { 2 - 5 } & $3-11$ & $10-20$ & $250-500$ & $0.058-0.069$ \\
\hline \multirow{4}{*}{ Damansara } & $11-25$ & $18-50$ & $500-800$ & 0.058 \\
\cline { 2 - 5 } & $0-5$ & $6-18$ & $80-200$ & $0.000002-$ \\
& $5-10$ & $18-30$ & $200-600$ & 0.108 \\
\cline { 2 - 5 } & $10-16$ & $30-50$ & $600-800$ & 0.099 \\
\hline
\end{tabular}

In this study, the frequency-response curve obtained from WinSASW programmed has been selected to interpret the damping of soil from the signal spectrum recorded from SASW test using the half- power bandwidth method. Generally, SASW method predicted similar characteristics of strain and damping, which decreased with depth. Analysis of the performed SASW field data in this study shows that the strain amplitudes caused by several assorted hammer as seismic source are generally less than $10^{-6} \%$. From this findings, clearly shows that SASW method tends to have a more linear behavior of soil and dynamic properties at small strains $\left(10^{-4} \%\right.$ or less $)$, conditions as shown in Fig. 1.

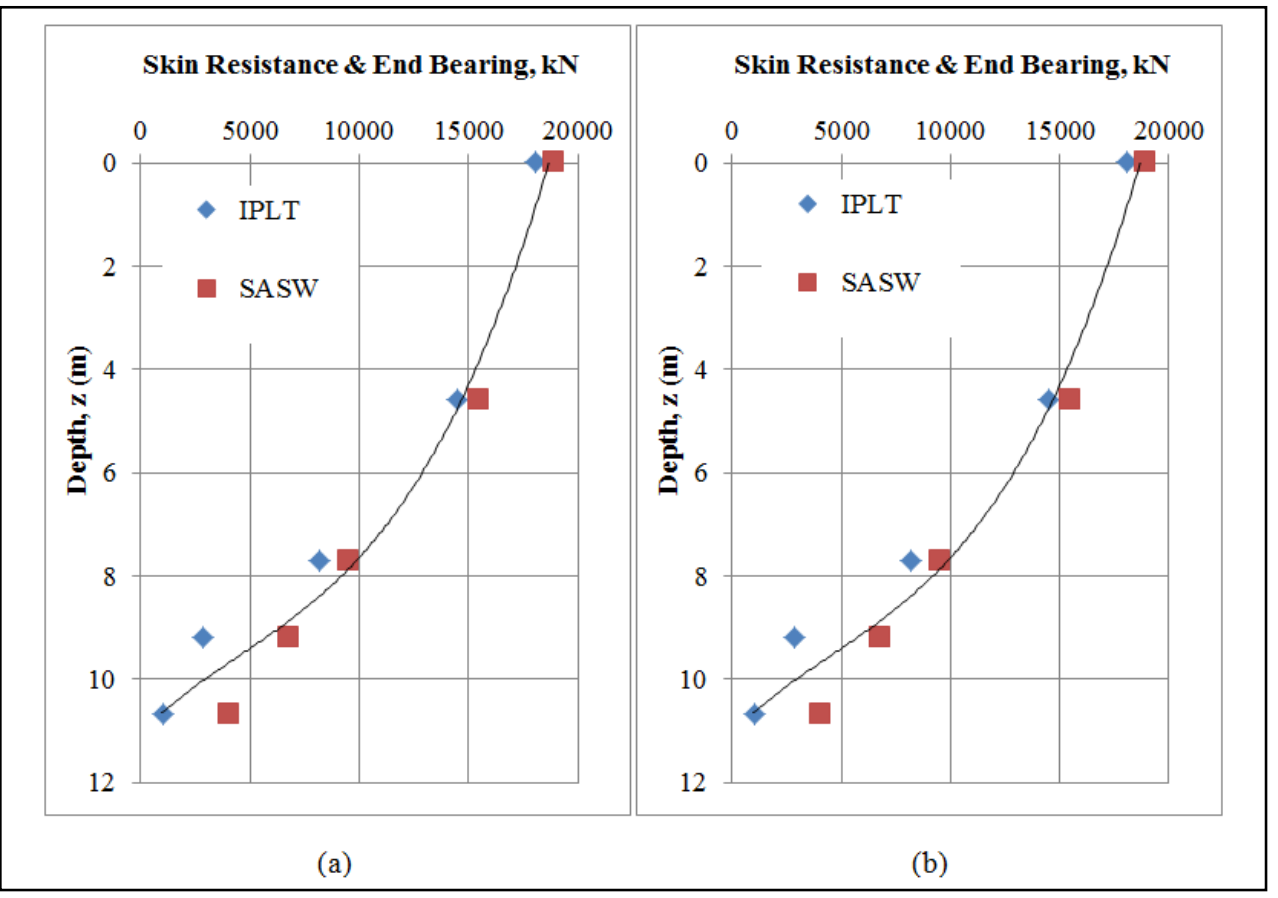

Fig. 1. Skin and end bearing resistances of pile at site of a) Kuala Lumpur and b) Damansara. 
For foundation design based on hyperbolic model, the two most important parameters are the modulus of soil and strain amplitude. Back analysis shows that the ultimate pile bearing capacity is equal to $4947 \mathrm{kN}$ and $18891 \mathrm{kN}$ at small strain levels of about $10^{-5}$ to $10^{-6} \%$ for sites of Kuala Lumpur and Damansara, respectively. The result of normal and shear stress of soil [9] was used to determine skin and end bearing resistance of pile as shown in Figure 3. This ultimate pile bearing capacity is in close agreement with the results of instrumented pile load test at site as tabulated in Table 2. The small difference shows that the estimated ultimate pile bearing capacity are in really good agreement and the difference might be due to stress oscillation and the average values used in this study.

Table 2. Comparisons of ultimate pile bearing capacity between IPLT and SASW methods.

\begin{tabular}{|c|c|c|c|}
\hline \multirow{2}{*}{ Site } & \multicolumn{2}{|c|}{ Ultimate Pile Bearing Capacity (Qult) kN } & \multirow{2}{*}{$\begin{array}{c}\text { Difference } \\
\text { (\%) }\end{array}$} \\
\cline { 2 - 3 } & SASW & IPLT & 6 \\
\hline Kuala Lumpur & 4947 & 4633 & 5 \\
\hline Damansara & 18981 & 18014 & \\
\hline
\end{tabular}

\section{Conclusions}

Based on the results performed in this study, the shear wave velocity and damping measurements obtained using SASW test able to evaluate the ultimate pile bearing capacity. An empirical equation [9] is back calculated to predict the ultimate pile bearing capacity and the outcomes were compared with the conventional results. The $6 \%$ and $5 \%$ difference of the amount ultimate pile bearing capacity obtained in this study justified that ultimate pile bearing capacity can be measured using shear wave velocity and damping measurements for Kuala Lumpur and Damansara, respectively. Furthermore, this percentage is less than $10 \%$ of the standard acceptance in the design of conventional civil engineering structures.

\section{References}

1. S. Nazarian, K.H. Stokoe II, Austin, Texas, (1985)

2. C. P. Abbiss, Géotechnique 31(1), 91-104, (1981)

3. G.J. Rix, C.G. Lai, M.C. Orozco, G.L. Hebeler, V. Roma, Proceedings of the fifteenth International Conference on Soil Mechanics 1-3(3), 499-502, (2001)

4. A. Hara, T. Ohta, M. Niwa, S. Tanaka, T. Banno, Japaneses Society of Soil Mechanics and Foundation Engineering 14(3), (1974)

5. T. Inazaki, The Proceedings of IWAM04, Mizunami, Japan, hlm. S4, (2004)

6. S.S. Tezcan, A. Keceli, Z. Ozdemir, Geotechnical and Geological Engineering 24(1), 203-218, (2006)

7. R.V. Whitman, S. Liao, Vicksburg, Mississipi, (1985)

8. C.P. Abbiss, Géotechnique 36(4), 565-580, (1986)

9. B.O. Hardin, V.P. Drnevich, Journal of the Soil Mechanics and Foundations Division, SM 7(9006) $667-692$, (1972) 
10. S.A. Badsar, M. Schevenels, G. Degrande, ECCOMAS Thematic Conference on Computational Methods in Structural Dynamics and Earthquake Engineering, (June), (2009)

11. S. Foti, Géotechnique 53(5), 455-461, (2003)

12. C.G. Lai, G.J. Rix, S. Foti, V. Roma, Soil Dynamics and Earthquake Engineering 22(9-12), 923-930, (2002)

13. C.P. Abbiss, Géotechnique 33(4), 397-405, (1983)

14. S.H. Joh, T.H. Kang, D.W. Jang, I.-W Lee, Journal of the Korean Geotechnical Society. Korean Geotechical Society 21(4), 71-81' (2005)

15. A. Keçeli, Jeofizik 16, 17-29, (2012) 